\title{
Correlation analysis of IMO collision damage parameters
}

\author{
J. Parunov, M. Ćorak \& S. Rudan \\ Faculty of Mechanical Engineering and Naval Architecture, University of Zagreb, Zagreb, Croatia
}

\begin{abstract}
The aim of the present paper is to investigate a correlation between collision damage parameters, which could improve Monte Carlo simulation of random collision damages and facilitate its implementation into the risk assessment of maritime transportation. The proposed approach is based on the explicit LS-Dyna simulation of the collision between a ferry and an Aframax tanker, as striking and struck ship respectively. Numerical simulations are then approximated by the surrogate model enabling evaluation of damage for different random collision scenarios characterized by striking ship speed, collision angle, collision location and displacement mass. Monte Carlo simulation of random collision scenarios is then employed to obtain histograms of damage parameters that can be compared to IMO probabilistic models. Such approach enables not only comparison of damage size histograms between IMO and numerical simulations but also establishing mutual correlation among damage length, breadth and height. Finally, the established correlation is employed into the IMO probabilistic model of random damage parameters and consequences on probabilistic models of residual ultimate strength and still water bending moments are discussed.
\end{abstract}

\section{INTRODUCTION}

Probabilistic models of damage size and location are crucial in the post-accidental safety analysis of a ship damaged by collision or grounding (Faisala et al. 2015). Such random damage parameters can be either calculated by numerical collision/ grounding simulation or assumed according to the probabilistic models proposed by IMO Resolution MEPC 2003 (Youssef et al. 2014, IMO 2003). Former is more realistic, as damage depends on a number of parameters, but is rather time consuming, while the latter assumes damage regardless of the cause of the damage, but it is computationally efficient. IMO model proposes the extension and location of damage in the hull through a 'damage box', i.e. a rectangular parallelepiped with given dimensions in the three directions of space: length, height, breadth and a location of the box in addition. These variables are assumed as mutually independent, which is not satisfactory assumption, as it could result in strange and physically unrealistic damages (Prestileo et al. 2013). The aim of the present study is to investigate correlation between collision damage parameters that could improve Monte Carlo (MC) simulation of random collision damages and facilitate its implementation in the risk assessment of maritime transportation.

The proposed approach is based on the explicit LS-Dyna simulation of the collision between a ferry and an Aframax tanker, as striking and struck ship respectively (Parunov et al. 2016). Numerical simulations are then approximated by surrogate model enabling fast computation of damages for different collision scenarios characterized by striking ship speed, collision angle, collision location and displacement mass. MC simulation of random collision scenarios is then employed with surrogate model to obtain histograms of damage parameters that can be compared to IMO probabilistic models. Such approach enables comparison of histograms of damage size between IMO and numerical simulations as well as establishing a mutual correlation between damage length, breadth and height.

Correlation is then employed to the IMO probabilistic model of random damage parameters and differences on probability density functions are observed. Consequences of the correlation on the two main pertinent random variables influencing hull girder safety of damaged ship - residual ultimate strength and still water bending moment, are studied. Conclusions about practical importance of correlation among random damage parameters are finally drawn.

\section{LS-DYNA SIMULATION OF COLLISION}

In the present analysis, the Aframax class tanker is considered as the struck ship and a ferry as the striking ship (Parunov et al. 2016). The main particulars for both the struck and the striking ship are listed in Table 1. 
Table 1. Main struck and striking ship particulars.

\begin{tabular}{lll}
\hline & Struck ship (tanker) & Striking ship (ferry) \\
\hline $\operatorname{Lpp}(\mathrm{m})$ & 236 & 120 \\
$B(\mathrm{~m})$ & 42 & 19.6 \\
$D(\mathrm{~m})$ & 21 & 12.2 \\
$T(\mathrm{~m})$ & 15.1 & 5.3 \\
$\Delta(\mathrm{t})$ & 133000 & 6889 \\
\hline
\end{tabular}

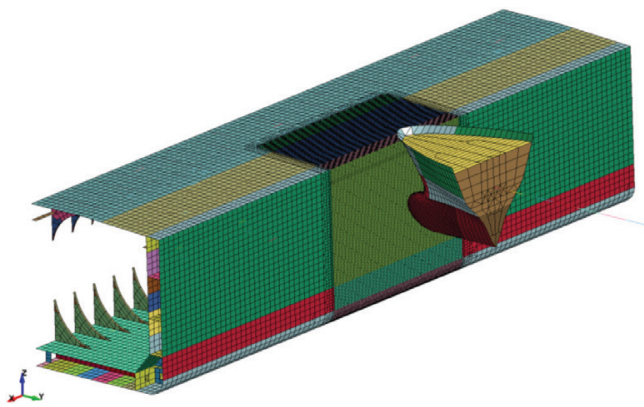

Figure 1. Reference model collision set-up.

Because a very fine mesh is required in the collision zone, only a portion of the struck ship is modelled, consisting of the half of three cargo holds. The striking ship bow is modelled in detail and the rest of the ship, i.e. the ferry hull, is modelled appropriately by beam finite elements. It should be clarified that the bow of the striking ship is modelled as an elasto-plastic structure. Reference collision scenario set-up is presented on Figure 1 and described by the following list of parameters:

- Ferry is located in front of the middle cargo hold of a tanker,

- Collision is orthogonal,

- Speed of the tanker is $0 \mathrm{~m} / \mathrm{s}$,

- Speed of the ferry is $8 \mathrm{~m} / \mathrm{s}$,

- Draft of the tanker is $15.1 \mathrm{~m}$,

- Draft of the ferry is $5.3 \mathrm{~m}$

A number of FEM analyses were performed and the following main parameters varied (Galletta 2015):

- Ferry collision speed: $2 \mathrm{~m} / \mathrm{s}, 4 \mathrm{~m} / \mathrm{s}, 6 \mathrm{~m} / \mathrm{s}, 8 \mathrm{~m} / \mathrm{s}$ (reference model), $10 \mathrm{~m} / \mathrm{s}$ and $12 \mathrm{~m} / \mathrm{s}$.

- Impact location $\mathrm{x}=87 \mathrm{~m}$ (aft cargo hold collision), $\mathrm{x}=118 \mathrm{~m}$ (reference model), $\mathrm{x}=148.5 \mathrm{~m}$ (bow cargo hold collision).

- Impact angle: $-45^{\circ},-30^{\circ},-15^{\circ}, 0^{\circ}$ (reference model), $15^{\circ}, 30^{\circ}$ and $45^{\circ}$.

- Scaled striking ship length/mass: $4251 \mathrm{t}, 6889 \mathrm{t}$ (reference model), 13226 t, $23329 \mathrm{t}$ and $41149 \mathrm{t}$.

Considering that collision is orthogonal, i.e. impact angle is 90 degrees, and occurs approxi-

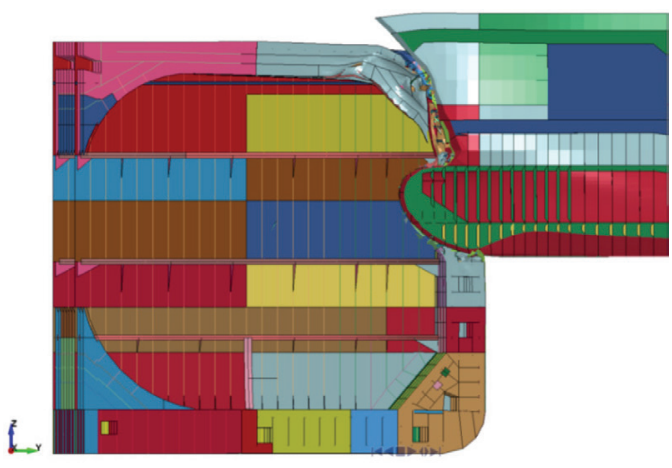

Figure 2. Reference model at the end of simulation.

mately at the middle of the struck ship length; it is assumed that the only external dynamic effect to be taken into account is the sway motion of the struck ship. In particular, $40 \%$ of the mass is added to the struck ship displacement mass to take into account the sway resistance, as proposed by e.g. Minorksy (1959) and Motora (1971) (for a short duration collision).

Particular attention was paid to the definition of the fracture strain since it is used as a failure criterion during the analysis. Fracture strain is a function of the finite element size and thickness and Peschmann criterion is applied to take both of these parameters into account. Finite element thickness in the collision zone varies from 10 to $28.5 \mathrm{~mm}$ while the finite element size in that area is exactly or as close as possible equal to $100 \times 100 \mathrm{~mm}$. Consequently, failure strain is reduced from the ultimate failure strain obtained from a true stressstrain curve, being equal to 0.27 , to effective failure strain ranging from 0.145 to 0.265 .

True stress-strain curve for common structural Grade A steel with yield strength of $235 \mathrm{MPa}$ is obtained from the standard tensile strength experiment performed in-house. True-stress strain curve is introduced into piecewise-linear elastic-plastic material model, i.e. MAT124 in LS-Dyna, used for the performed non-linear FE analyses.

An automatic surface to surface contact algorithm was used to model contact between the ships in collision (Livermore Software Technology Corporation, 2014).

Situation at the end of reference model collision simulation is presented on Figure 2. Due to the variation of the main parameters, hull breach will not be present in every collision scenario and the damage will vary too. Destruction of the structure and the plastic strain in the damaged area for the reference model is presented on Figure 3. On the same figure the method of the damage volume measurement is indicated. 


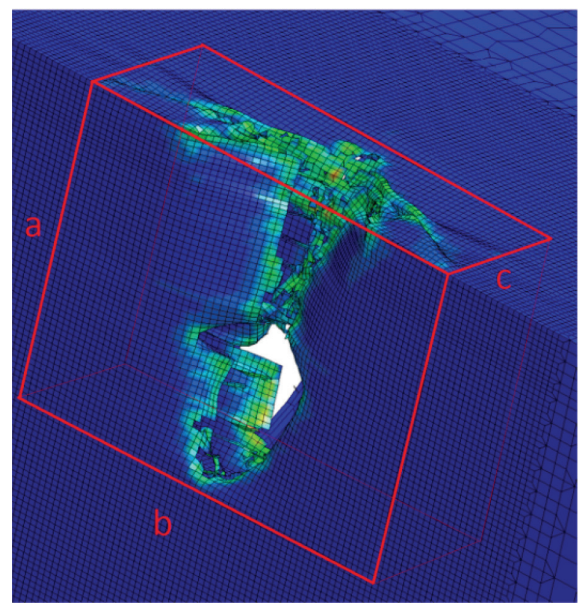

Figure 3. Destruction of the structure and the plastic strain.

Struck ship structural damage consists of bulb induced rupture and fore peak induced damage. Structural damage is three-dimensional and consists of material that completely failed (eroded elements in FE calculation), material that is subjected to plastic deformation and material that is subjected to elastic deformation. This defines the volume of structural damage and the quantification of that volume is not straightforward. It is assumed that total width $b$, height $a$ and depth $c$ of the plastic deformation zone define the "damage box" of the structure. Within the "damage box" there are areas subjected to plastic damage, but also areas subjected to significant amount of elastic deformation. Consequently, internal mechanics part of collision energy is spread throughout the nearly entire "damage box".

To determine directly the damage size for a large number of random collision parameters, time consuming and expensive numerical simulations are required. To overcome that difficulty, dimensions $a, b$ and $c$ of the damage box are presented as a regression curves depending on the collision scenario parameters. Curves are presented in Figure 4.

It is assumed that the consequences of the collision are the same irrespective of the location along the cargo hold. This is obviously not true, as the damage size would not be the same if collision occurred at the bulkhead or in the middle of the cargo hold, for the same combination of collision parameters.

Also, the dependence of the damage size on the vertical location of the damage is not considered in the present paper. That would be of importance
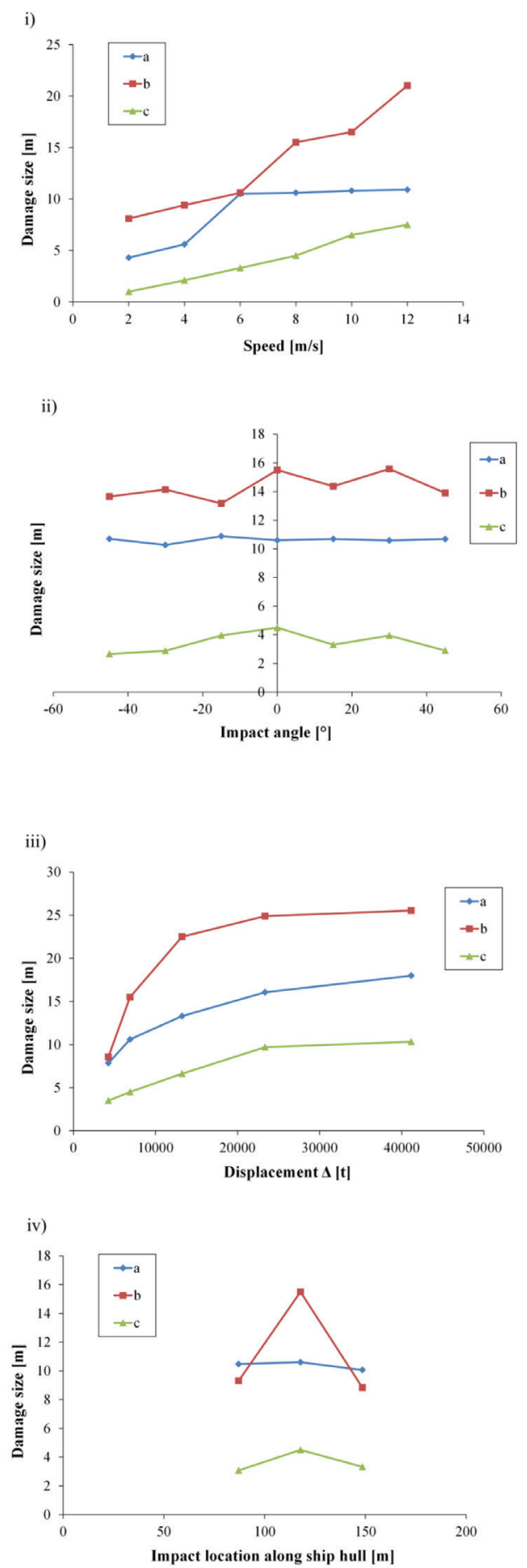

Figure 4. Dependence of a damage size on collision speed (i), impact angle (ii); striking ship displacement (iii); impact location along ship hull (iv). 
i)

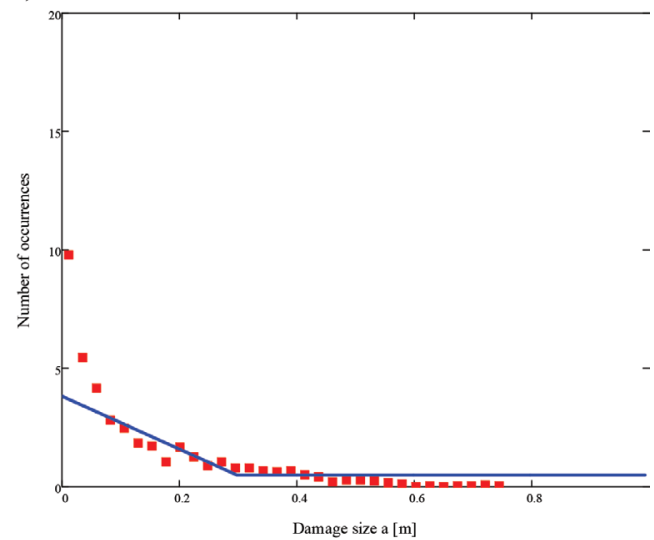

ii)

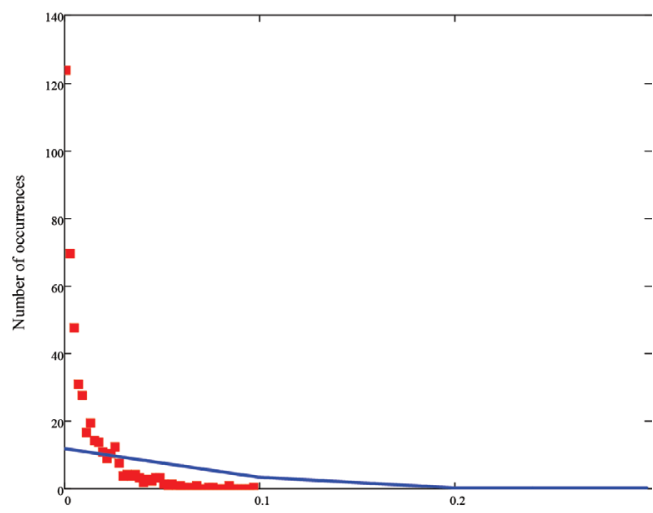

iii)

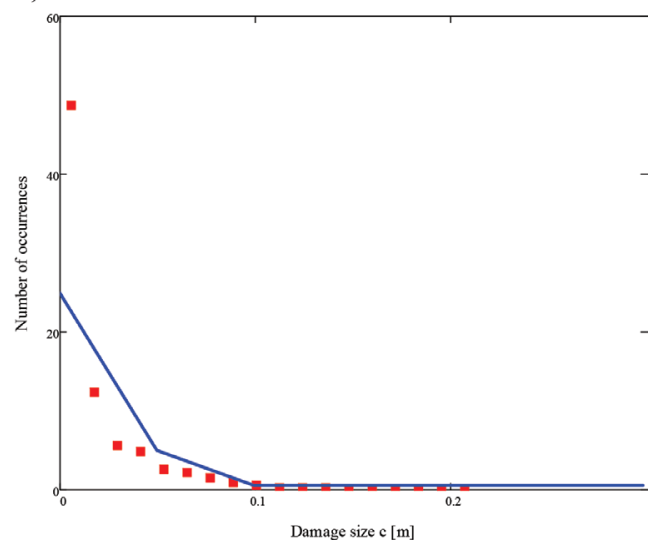

Figure 5. Results of MC simulation of damage size, damage height $a$ (i); damage length $b$ (ii); damage depth $c$ (iii).

if, for example, different drafts of the struck ship were concerned. However, for the tanker in full load condition, the vertical location of the collision remains nearly the same.

\section{MONTE CARLO SIMULATION OF RANDOM COLLISION SCENARIOS}

Probability distribution of the striking vessel speed is assumed normal with a mean value equal to $13.3 \mathrm{kn}$ and a standard deviation of $5.1 \mathrm{kn}$. These data are obtained by AIS in the Adriatic Sea (Zec et al. 2009). Collision speed of the striking vessel is conditioned by the service speed and is uniformly distributed between the zero speed and $75 \%$ of the service speed, after which it linearly decreases to zero at service speed (Klanac et al. 2013). On the other hand, the speed of the struck tanker is assumed to be equal to zero. Collision angle is assumed to be normally distributed, with the mean value of $3^{\circ}$ and a standard deviation of $42^{\circ}$, whereas the distribution of collision location is uniform. Collision angle and location along the struck vessel are assumed on the basis of previous worldwide collision accidents data (Klanac et al. 2013). Probability density function of the displacement of the striking ship is assumed to have exponential distribution with the expected value equal to $6700 \mathrm{t}$, based on the traffic data in the Adriatic Sea (Zec et al. 2009).

Monte Carlo simulation is performed based on described probabilistic collision scenario and damage size parameters $a, b$ and $c$ are determined from Figure 4. Results of $1000 \mathrm{MC}$ simulations are presented in Figure 5, together with the probability density functions from IMO Resolution MEPC (IMO 2003).

By comparing the results of $\mathrm{MC}$ simulation with IMO model, it appears that the outcome of MC simulations results in the much higher probabilities of small damages. However, the trends between both methods seems to be the same, especially for damage height $a$ and damage depth $c$. The bow of the striking ferry used in the simulation is relatively short and narrow and it is consequently expected that IMO distributions have higher probabilities of large damages.

\section{CORRELATION ANALYSIS}

Mutual dependency between the three parameters of the damage box used in the analysis is presented in Figure 6.

A very strong positive correlation between damage size parameter may be observed, as the coefficient of determination $R^{2}$ is in all three cases higher than 0.8 . In order to further quantify strength of the correlation between variables, Pearson and Spearman correlation coefficients are calculated and presented in the Table 2 .

Values in Table 2 indicate strong correlation in all cases and the conclusion is that correlation 


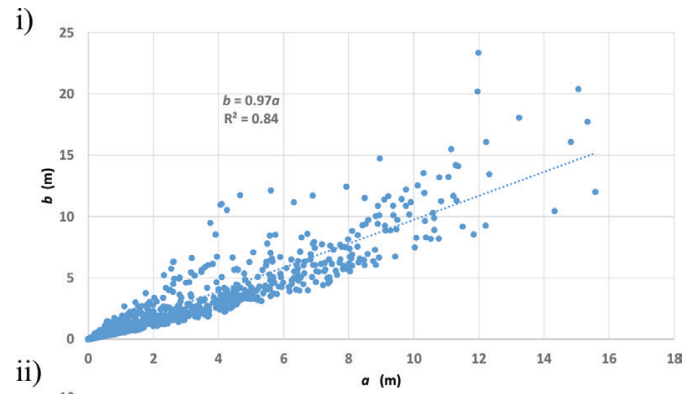

ii)

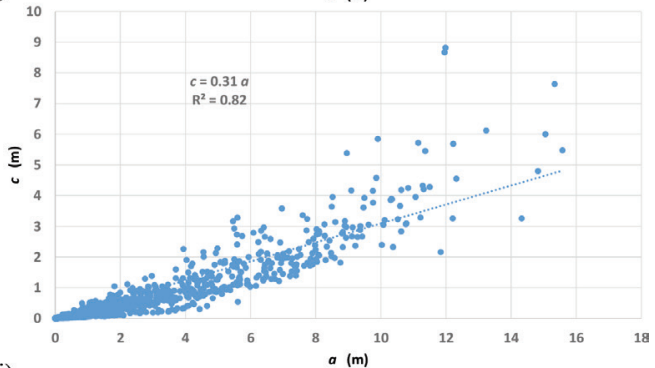

iii)

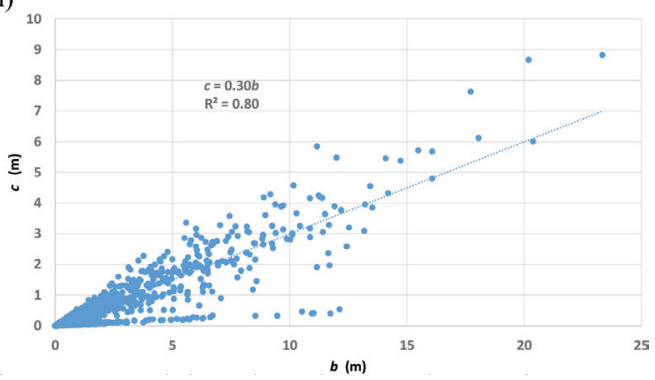

Figure 6. Mutual dependency between damage size parameters, damage height $a$ vs damage length $b$ (i); damage height $a$ vs damage depth $c$ (ii); damage width $b$ vs damage depth $c$ (iii).

Table 2. Correlation coefficients.

\begin{tabular}{llll}
\hline Coefficient & $a-b$ & $a-c$ & $b-c$ \\
\hline Pearson & 0.92 & 0.91 & 0.90 \\
Spearman & 0.97 & 0.96 & 0.90 \\
\hline
\end{tabular}

should not be neglected when performing MC simulation according to the IMO probabilistic model.

In order to facilitate numerical simulation of the correlation between damage parameters, data from Figure 6 are rearranged in terms of their mean values and standard deviation and are presented in Figure 7.

In total, 10000 simulations are used to obtain diagrams in Figure 7. Number of simulations is increased, when compared to the analysis presented in previous section, in order to obtain satisfactory number of outcomes in the whole range i)

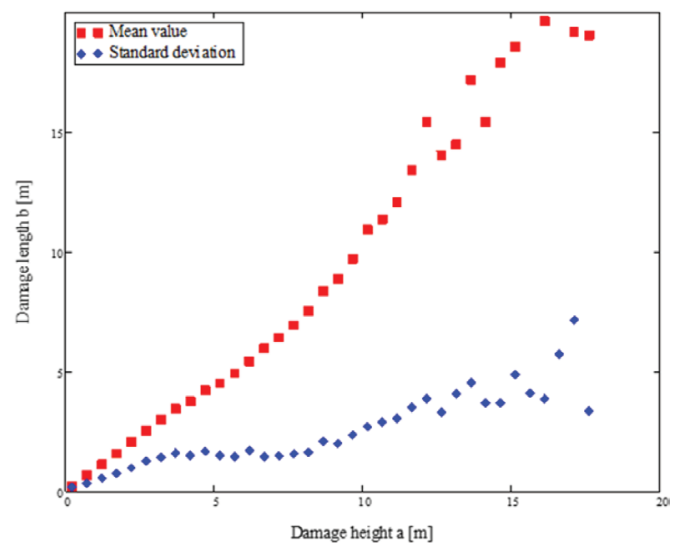

ii)

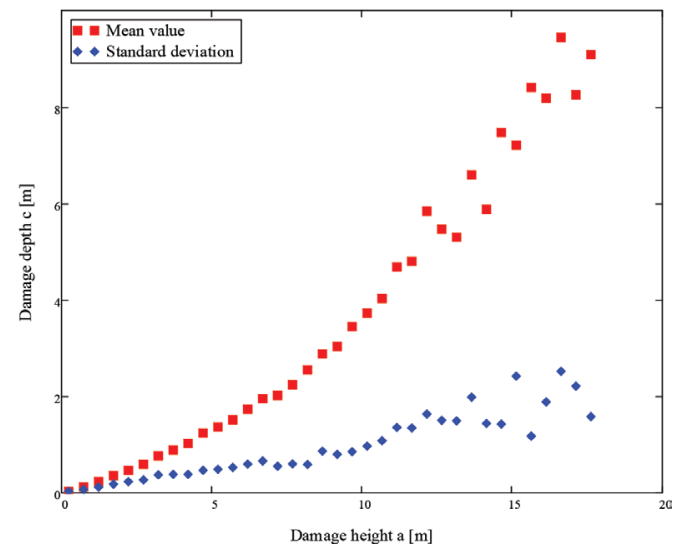

Figure 7. Mean values and standard deviations of damage length $b$ vs damage height $a$ (i); damage depth $c$ vs damage height $a$ (ii).

of parameters. Damage height $a$ is grouped into bins with $0.5 \mathrm{~m}$ width, and then mean values and standard deviation of damage length $b$ and width $c$ are determined for each bin. Therefore, if damage height $a$ is known, then graphs presented in Figures 7 enable computation of expected values and standard deviations of damage length $b$ and damage depth $c$.

As an example of the calculation of the mean values and standard deviations, 2078 simulations resulted in damage height $a$ between 0 and $0.5 \mathrm{~m}$. For those simulations, mean and standard deviations are calculated for damage length $b$ and damage width $c$ associated with each $a$. That mean value and standard deviation is plotted in Figure 7 for first bin $(a=0-0.5 \mathrm{~m})$. Such procedure is repeated for other bins until highest one, $a=17.5-18 \mathrm{~m}$, where only 3 simulations are recorded. 
i)

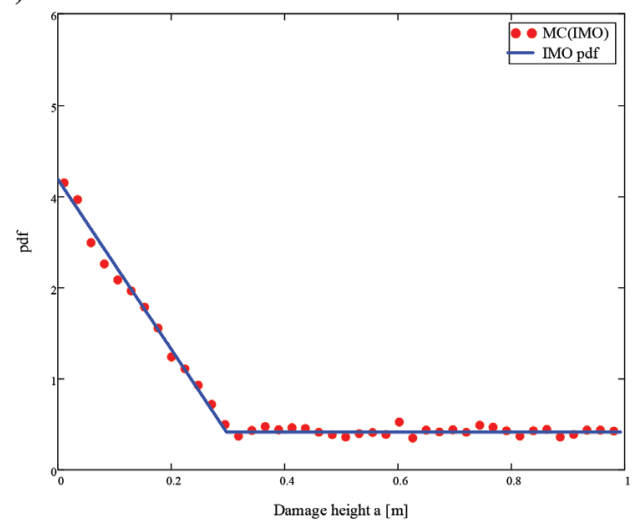

ii)

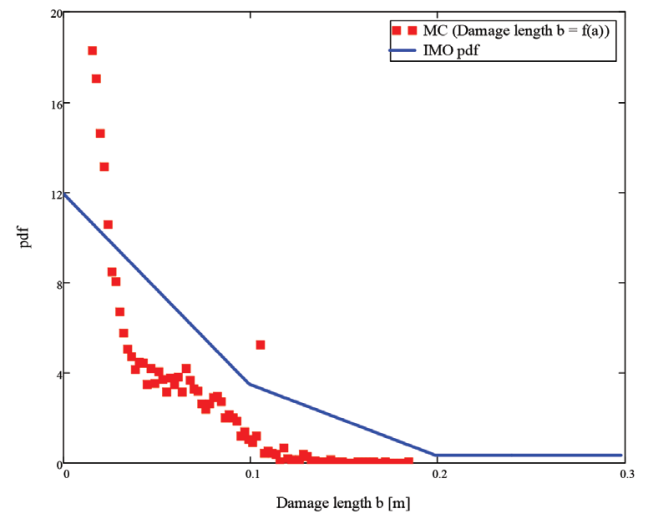

iii)

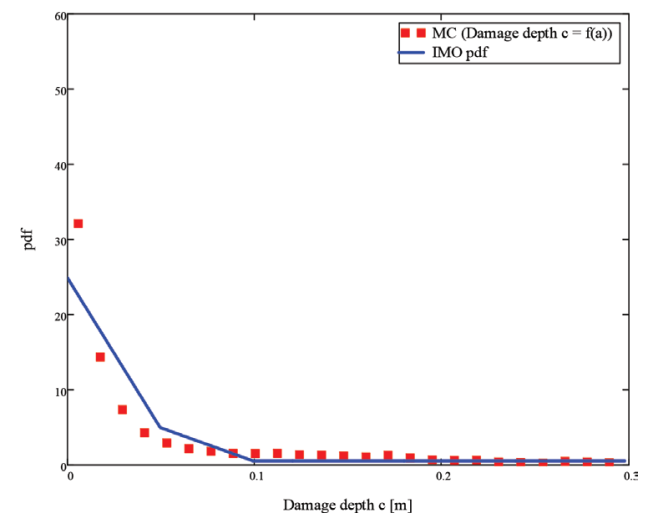

Figure 8. Results of MC simulation of damage size including correlation between damage parameters, damage height $a$ (i); damage length $b$ (ii); damage depth $c$ (iii).

IACS (2014b) assumed deterministic relationship between a damage height and a penetration depth based on the results of HARDER project. Such approach is equivalent to the full correla- tion assumption. The present approach represent an advancement as the relationship between damage parameters is obviously not deterministic and the correlation is not perfect, as it may be clearly seen by the existence of the standard deviations in Figure 7.

It is interesting to compare a relationship between a damage height and a damage penetration depth between IACS (2014b) and present study. Thus, for a damage height of $0.75 \mathrm{D}$ $(15.75 \mathrm{~m})$, IACS $(2004 \mathrm{~b})$ proposes damage penetration depth of $0.122 \mathrm{~B}(5.124 \mathrm{~m})$. In the present study, for the same damage height, damage depth calculated from linear regression equation on Figure 6 (ii) reads $4.88 \mathrm{~m}$. Thus, results obtained in the present study seem to be credible. However, expected value from Figure 7 (ii), would result in a larger penetration depth. The reason is that expected penetration depth actually follows the non-linear trend as a function of damage height that is not considered in IACS (2014b).

\section{IMO MODEL WITH CORRELATION}

The assumption inherent in the IMO model of ship collision is that damage parameters $a, b$ and $c$ are mutually independent and hence uncorrelated random variables. As shown in the preceding section, this is obviously not justified assumption. In order to study possible implications of such incorrect assumption, $\mathrm{MC}$ simulations are performed based on the results obtained in Section 4.

Firstly, damage height $a$ is simulated based on IMO recommended probabilistic model. Then, damage length $b$ and transverse penetration depth $c$ are simulated using mean values and standard deviations from Figure 7. Results of such MC simulation are presented in Figure 8.

As may be seen from Figure 8, there are some differences between simulated damage length and depth with respect to the IMO probability density functions. However, it is very interesting to notice that the damage penetration depth $c$ is quite similar to IMO model. As expected, damage height $a$ is the same as IMO model, as $a$ is simulated directly from IMO pdf.

\section{CONSEQUENCES OF THE CORRELATION}

Collisions can have severe consequences, including in some cases the total loss of a ship. After the event of collision, struck ship may capsize rapidly due to a lack of stability, sink gradually or stay afloat. If the ship stays afloat after collision, hull-girder collapse may occur when the hull's maximum residual 
load-carrying capacity (the ultimate hull girder strength, the bending moment capacity) is insufficient to sustain the corresponding hull girder loads applied. The collapse of hull girder may lead to a massive oil spill which eventually causes environmental pollution (Jia and Moan 2008).

The most obvious consequence of collision damage is the reduction of the ultimate bending moment capacity. The Progressive Collapse Analysis (PCA) method initially proposed by Smith represents nowadays the most frequently used method for ultimate strength assessment (Hughes and Paik 2013). The crucial part of the Smith's method is a stress-strain relationship for beam columns, of which stiffened panels forming the ship hull are composed. Stress-strain relationships most frequently used nowadays are those proposed by IACS CSR-H (IACS, 2014a). The ultimate bending moment is then calculated by an incrementally iterative procedure. If PCA method is applied to the damaged ship, it is assumed that damaged elements are completely removed from the section. This so-called 'damaged element removal method' has been used in several related studies (Youssef et al. 2014) and is also used here to model the hull damage by PCA.

Based on the PCA results, design curves are developed showing dependency of the residual ultimate strength in sagging on the damage extent, Figure 9. It is conservatively assumed that collision damage always starts from the main deck. Upper curve in Figure 9 is used for the case when only outer shell is damaged, while the lower curve is used when both outer and inner shell are breached. The latter curve includes also the influence of the rotation of neutral axis on the ultimate strength of damaged ship in sagging (Bužančić Primorac, 2016).

Probabilistic reduction of ultimate residual strength is calculated in a way that for each outcome of MC simulation, reduction of the ultimate

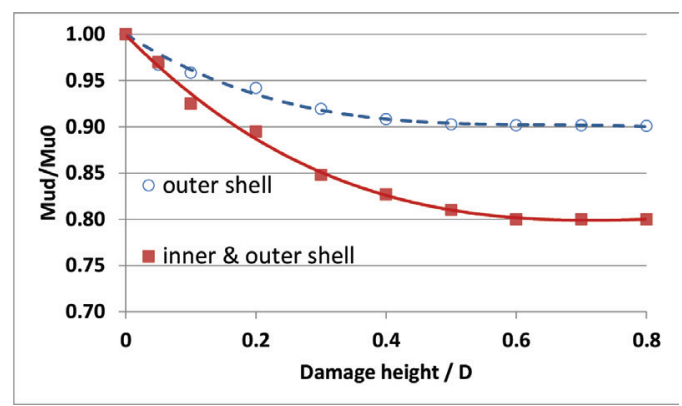

Figure 9. Reduction of ultimate longitudinal strength of damaged Aframax oil tanker (Bužančić Primorac, 2016). strength is calculated using curves from Figure 9. Thus, two histograms are obtained - one for original IMO model and another one using IMO model only for damage height, while correlation model for damage transverse penetration depth. It is to be noted that the damage length is not important for the strength reduction if "damage element removal method" is used. Results of the analysis for two MC simulation are shown in Figure 10.

Average loss of the ultimate strength reads $6.2 \%$ and $7.8 \%$ for the cases without and with the correlation respectively. Number of the cases with the inner hull damage reads $25.7 \%$ and $27 \%$ for the case of original distribution and when correlation is accounted for, respectively. Although the influence of correlation is not very large regarding the mean value of the ultimate strength loss or a number of cases with inner hull damage, there is an obvious difference in Figure 10 between the two calculation models. Model with correlation estimates a much larger number of severe ultimate strength reductions (between 12 and 22\%) and also a larger number of very low strength reductions (less than 5\%).

Probabilistic models of the residual strength index of oil tankers of different sizes are studied by Faisal et al. (2015). Lower strength reductions of a struck ship are obtained in that studies compared to the present one, probably as a consequence of the more realistic assumptions regarding damage location. In the present study, namely, conservative assumptions that the damage starts from the main deck and that it has regular box shape, are adopted.

Still water loads can be evaluated from the proper consideration of the mass and buoyancy distribution over the ship length. In a damaged condition, effects of flooding of different types

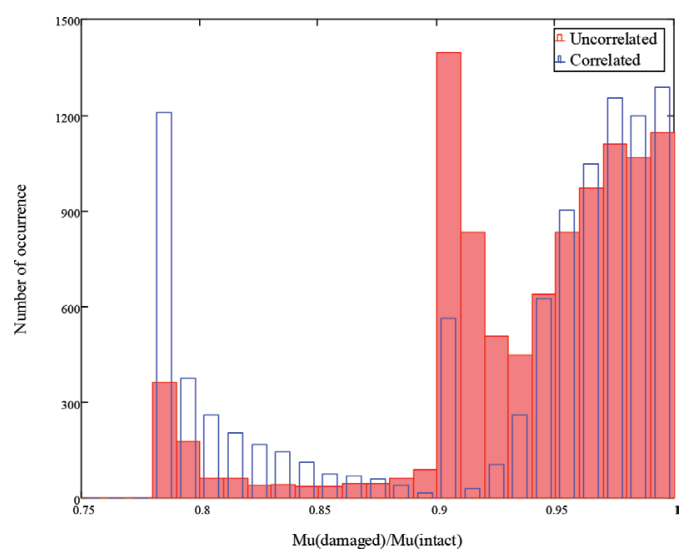

Figure 10. Histogram of loss of ultimate strength for sagging condition. 
of ship compartments and the corresponding oil outflow are to be taken into account. After damage, the Still-Water Bending Moment (SWBM) can change considerably due to the increase of the weight (Hussein and Guedes Soares 2009).

Hydrostatic analysis of a damaged ship is performed herein using VeriSTAR Stability software (Bureau Veritas 2009). Only full load condition on the scantling draught is considered in the present analysis. One example of calculated SWBM distribution of a damaged ship is shown in Figure 11. Increase of SWBM in damaged condition, not only with respect to SWBM of intact ship but also beyond permissible seagoing SWBM, may be noticed in Figure 11.

For many damage scenarios, static equilibrium position distribution of SWBM along the ship were found. In total, 54 different damage cases are analysed to cover all possible collision damage scenarios. For SWBM of damaged ship, damage location, length and penetration depth are important while damage height has not been used.

Probabilistic change of SWBM is calculated in a way that for the outcome of each MC simulation, a change in maximum SWBM is obtained using one of 54 collision damage cases, depending on damaged compartments. Thus, histograms shown in Figure 12 are obtained, where abscissa represents the ratio of maximum SWBM in damaged condition to maximum SWBM of the intact ship. Two histograms are presented in Figure 12 - one for simulation with original IMO probabilistic model and one for simulation with correlation model.

The mean value for IMO model reads $92 \%$ of the intact SWBM, while standard deviation reads 0.43 . The mean and standard deviation for
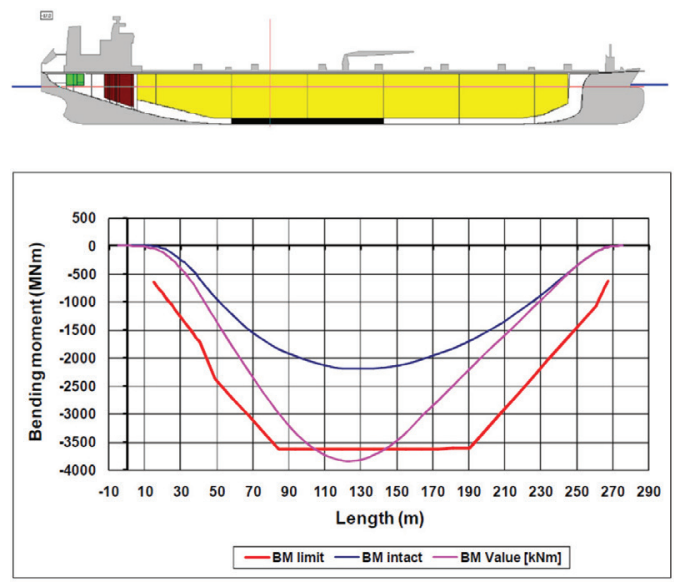

Figure 11. Comparison of SWBM diagrams for intact ship and collision damage of WBT 4\&5(S) (Bužančić Primorac, 2016).

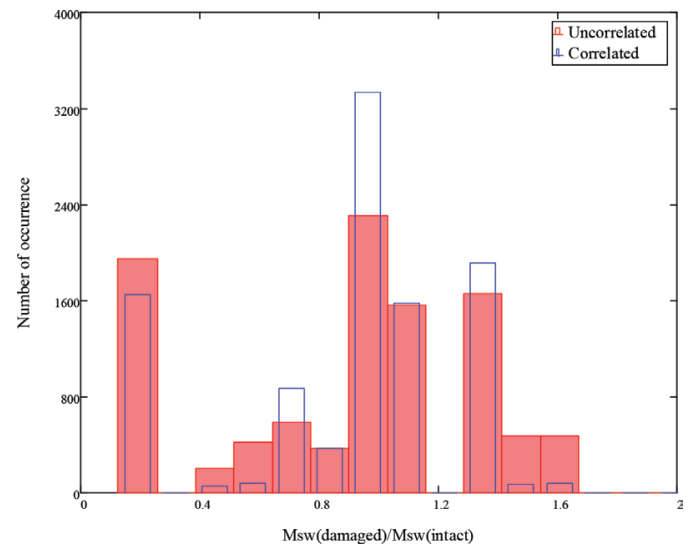

Figure 12. Histogram of the ratio of maximum SWBM in damaged to the maximum SWBM in intact condition.

the model with correlation read $92 \%$ and 0.36 respectively.

It may be seen that two models result in the same mean value but standard deviation of the correlated model is lower. This is probably related to the fact that the correlation reduces damage length, a parameter having decisive factor on damaged ship SWBM. It may be seen from Figure 12 that, for the correlated model, in most of damage cases SWBM is similar to the intact ship, while the number of damage cases with large increase of SWBM is reduced compared to the original IMO model.

\section{CONCLUSIONS}

The aim of the paper is to investigate the existence of a correlation between collision damage parameters and to analyze implications that such correlation might have on the main variables influencing the safety of a damaged ship.

The correlation study is based on the explicit LS-Dyna simulation of a collision between a ferry and an Aframax tanker, as striking and struck ship respectively. MC simulation of random collision scenarios is employed to obtain mutual correlation among damage length, breadth and height. It is clearly demonstrated that there is a strong correlation between mentioned collision damage parameters.

Correlation is than employed to IMO probabilistic model, enabling comparison of the IMO model for the case with and without correlation. Consequences of the correlation on the probabilistic models of the random residual ultimate strength and random change of the still-water bending moments are studied by MC simulation. It is shown that correlation leads to more severe reduction of 
the residual strength compared to the IMO probabilistic model without correlation. Mean value of the change of maximum SWBM is almost the same for IMO and correlated models, while standard deviation is slightly reduced in the latter case.

The simulations performed in the present study correspond to one specific collision scenario where striking ship is a ferry. The results obtained reflect the damages due to a particular bow shape and size and a particular vertical impact location, as these two aspects have not been considered in the MC simulation. Other collision scenarios should be studied to quantify the correlation between the damage parameters with more confidence.

\section{ACKNOWLEDGEMENTS}

This work has been fully supported by Croatian Science Foundation under the project 8658.

\section{REFERENCES}

Bureau Veritas, VeriSTAR Stability Quick Start Manual, Bureau Veritas, 2009.

Bužančić Primorac, B. 2016., Structural reliability of damaged oil tanker, PhD thesis, University of Zagreb (in Croatian), supervisor: Joško Parunov.

Faisala, M., Noh S.H., Kawsar R.U., Youssef S., Seoa, J.K., Ha Y.C., Paik, J.K., 2016. Rapid hull collapse strength calculations of double hull oil tankers after collisions, Ships and Offshore Structures, DOI:10.1080/ 17445302.2016.1192747

Galletta M., 2015. Parametric analysis of collision between a tanker and a ferry, University of Genova, Master Thesis, course: Naval Architecture, supervisors: Cesare Mario Rizzo and Smiljko Rudan.

Hughes O.F. and Paik J.K., 2013. Ship structural analysis and design, The Society of Naval Architects and Marine Engineers, Alexander, USA.

Hussein, A.W. and Guedes Soares, C. 2009. Reliability and Residual Strength of Double Hull Tankers Designed According to the new IACS Common Structural Rules, Ocean Engineering 36, pp.1446-1459.
IACS. 2014a. Common Structural rules for Bulk Carriers and Oil Tankers. International Association of Classification Societies.

IACS, 2014b. Common Structural Rules for Bulk Carriers and Oil Tankers. International Association of Classification Societies, TB report no. Pt 1 - Residual strength, Ch 5, Sec 3.

IMO, 2003. Revised Interim Guidelines for the approval of alternative methods of design and construction of oil tankers under regulation $13 \mathrm{~F}(5)$ of Annex I of MARPOL 73/78, Resolution MEPC.110(49), International Maritime Organization.

Jia, H. and Moan, T. 2008. Reliability Analysis of Oil Tankers with Collision Damage, 27th International Conference on Offshore Mechanics and Arctic Engineering, Estoril, Portugal. Paper number; 57102 .

Klanac, A., Duletić, T., Erceg, S., Ehlers, S., Goerlandt, F., Frank, D., 2013, Environmental risk of collision of enclosed seas: Gulf of Finland, Adriatic and implications to ship design, 5th International Conference on Collision and Grounding of Ships, Espoo, Finland, pp. 55-65.

Livermore Software Technology Corporation, 2014. LSDYNA Keyword User's Manual R7.1 (revision: 5471).

Minorsky, 1959, An analysis of ship collision with reference to protection of nuclear power ships, J. Ship Res.; $3(2): 1-4$.

Motora S., 1971, Equivalent added mass of ships in collisions, Selected Papers from J Soci Nav Arch Japan.

Parunov J., Rudan S., Corak M., 2016, Ultimate hull-girderstrength-based reliability of a double-hull oil tanker after collision in the Adriatic Sea, Ships and Offshore Structures, DOI: 10.1080/17445302.2016.1254521

Prestileo, A., Rizzuto, E., Teixeira, A.P. and Guedes Soares, C. 2013. Bottom damage scenarios of the hull girder structural assessment, Marine Structures 33, pp. 33-55

Youssef, S.A., Faisal, M., Seo, J.K., Kim, B.J., Ha, Y.C., Kim, D.K., Paik, J.K., Cheng, F. and Kim, M.S., 2014, Assessing the risk of ship hull collapse due to collision, Ships and Offshore Structures, DOI: 10.1080/17445302.2014.993110

Zec, D., Maglić, L., Šimić Hlača, M., 2009, Maritime Transport and Possible Accidents in the Adriatic Sea, 17th Annual Conference of the European Environment and Sustainable Development Advisory Councils EEAC, Dubrovnik, Croatia. 